\title{
Skin compatibility of two ethanol based virucidal hand disinfectants
}

\author{
Bernhard Meyer ${ }^{1}$, Wolfgang Matthies' ${ }^{2}$ Joseph E. Nicholson ${ }^{3}$, and Morris V. Shelanski ${ }^{3}$ \\ ${ }^{1}$ Ecolab Deutschland GmbH, Düsseldorf, Germany \\ ${ }^{2}$ Henkel AG \& Co.KGaA, Düsseldorf, Germany \\ ${ }^{3}$ Product Investigations Inc., Conshohocken, USA
}

doi: 10.3396/ijic.V6i2.013.10

\begin{abstract}
Two virucidal hand rubs containing high concentrations of ethanol were evaluated for irritating and sensitizing propensities in a Human Repeated Insult Patch Test (HRIPT). Whereas the numbers of responses elicited by Product $A$ and an ethanol control were commensurately low and not significantly different $(p<0.256)$, the number elicited by Product B was significantly higher than those elicited by either Product A or control $(p<0.001)$. Product A was found to be devoid of clinically significant irritating propensities; Product B was a weak cumulative irritant. High concentrations of ethanol can be used in formulating highly effective virucidal hand disinfectants without compromising the skin compatibility of the product.
\end{abstract}

\section{Key Words}

hand disinfection, virucidal, skin compatibility, alcohol

\section{Introduction}

Hand hygiene is the most important measure in preventing the transmission of healthcare-associated infections. Although the importance of hand hygiene is widely acknowledged and promulgated by the World Health Organization, ${ }^{1}$ compliance of healthcare workers is, by and large, appalling. ${ }^{2,3}$ A compliance level of $<30 \%$ has been reported. ${ }^{4}$ This low rate may be partly due to misunderstanding the skin compatibilities of different hand hygiene procedures. Despite evidence that alcohol based hand rubs cause less damage to skin than detergent hand wash preparations, $5,6,7$ many healthcare personnel think the opposite, even in countries where they are usually considered to be more enlightened. ${ }^{8}$ Alcohol based hand rubs have been shown to reduce the number of pathogenic bacteria on the skin more effectively than soaps, whether plain ${ }^{9}$ or fortified with anti-microbial agents. ${ }^{10} \mathrm{~A}$ virucidal hand disinfectant such as a high concentration of ethanol should be used in high risk areas as well as

\section{Corresponding author}

Bernhard Meyer, Ecolab Deutschland GmbH, RD\&E Health Care, Reisholzer Werftstr. 38-42,

40589 Düsseldorf, Germany, Email: bernhard.meyer@ecolab.com 
during virus outbreak situations. Formulated products, containing moisturizers to increase compliance, with other ingredients to achieve a broad virucidal spectrum are preferred over pure ethanol whenever possible. We have compared the effect on skin of two such products formulated with high concentrations of ethanol with that of pure ethanol.

\section{Materials and Methods \\ Test products}

Product A: (Skinman complete, Ecolab, Düsseldorf, Germany): liquid dye-free hand disinfectant with $90 \mathrm{~g} / 100 \mathrm{~g}$ ethanol denatured with $1 \%$ butan-2-one as active ingredient, plus fragrance and moisturizer

Surgical hand disinfection according to EN 12791: $1.5 \mathrm{~min}$

Hygienic hand disinfection according to EN 1500: $20 \mathrm{sec}$

Virucidal according to guidelines of the German Society for the Prevention of Viral Disease: 2 min

Product B: (Sterillium virugard, Bode Chemie, Hamburg, Germany): liquid dye-free hand disinfectant with $95 \mathrm{~g} / 100 \mathrm{~g}$ ethanol denatured with $1 \%$ butan-2-one as active ingredient, plus petrol ether and moisturizer

Surgical hand disinfection according to EN 12791: $1.5 \mathrm{~min}$

Hygienic hand disinfection according to EN 1500: $30 \mathrm{sec}$

Virucidal according to guidelines of the German Society for the Prevention of Viral Disease: 2 min
EtOH: 90g/100g ethanol denatured with 1\% butan-2one in purified water was used as the active control.

\section{Test design}

A double-blind, active ingredient controlled, concurrent regimen comparison.

\section{Salient Features of the Method}

106 volunteers were studied. The study was conducted in conformance with the Good Clinical Practices (GCP) standards. A signed and witnessed informed consent was obtained from each participant.

Inclusion criteria: individuals of either sex between 18 and 70 years of age, who professed willingness to comply fully with the study regimen, and who expressed awareness that participation entailed incurring risks to general health and well-being.

Exclusion criteria: participation in another clinical trial; compromised health or immunological status; skin disorders that rendered the skin unsuitable for the purposes of the study; documented history of contact dermatitis arising from contact with the adhesive component of the patching devices; uncontrolled diabetes; medication with antihistamines, corticosteroids, beta-blockers, antibiotics, immunosuppressive drugs; recent vaccination; or the use of any medication that, in the opinion of the investigator, could enhance or diminish the individual's immune system's response. Additional exclusion criteria for females were: pregnancy or breast feeding.

Distribution of participants according to gender and age group is given in Table 1 .

Table I: Details of study participants

\begin{tabular}{lcccccc} 
Age group & $\mathbf{1 8 - 2 5}$ & $\mathbf{2 6 - 3 5}$ & $\mathbf{3 6 - 4 5}$ & $\mathbf{4 6 - 5 5}$ & $\mathbf{5 6 - 6 5}$ & $\mathbf{6 6 - 7 0}$ \\
\hline Number of females & 6 & 11 & 16 & 30 & 17 & 4 \\
\hline Number of males & 1 & 3 & 5 & 4 & 7 & 2 \\
\hline
\end{tabular}


Table II: Procedure of test product application and test site evaluation

\begin{tabular}{|c|c|c|}
\hline week & Day & Procedure \\
\hline \multirow[t]{6}{*}{1} & Monday & $\begin{array}{l}\text { Evaluation of effects (control reading before } 1 \text { st application), } \\
\text { 1st test product application }\end{array}$ \\
\hline & Tuesday & Patch removal, Evaluation of effects, 2nd test product application, same site \\
\hline & Wednesday & Patch removal, Evaluation of effects, 3rd test product application, same site \\
\hline & Thursday & Patch removal, Evaluation of effects, 4th test product application, same site \\
\hline & Friday & Patch removal, Evaluation of effects, no test product application \\
\hline & Saturday/Sunday & Rest phase \\
\hline \multirow[t]{6}{*}{2} & Monday & $\begin{array}{l}\text { Evaluation of effects (possible remaining effects from last Friday), } \\
\text { 5th test product application, same site }\end{array}$ \\
\hline & Tuesday & Patch removal, Evaluation of effects, 6th test product application, same site \\
\hline & Wednesday & Patch removal, Evaluation of effects, 7th test product application, same site \\
\hline & Thursday & Patch removal, Evaluation of effects, 8th test product application, same site \\
\hline & Friday & Patch removal, Evaluation of effects, no test product application \\
\hline & Saturday/Sunday & Rest phase \\
\hline \multirow[t]{6}{*}{3} & Monday & Holiday - rest phase \\
\hline & Tuesday & $\begin{array}{l}\text { Evaluation of effects (possible remaining effects from last Friday), } \\
\text { 9th test product application, same site }\end{array}$ \\
\hline & Wednesday & Patch removal, Evaluation of effects, 10th test product application, same site \\
\hline & Thursday & Patch removal, Evaluation of effects, 11 th test product application, same site \\
\hline & Friday & Patch removal, Evaluation of effects, 12 th test product application, same site \\
\hline & Saturday & Patch removal by volunteer himself \\
\hline 4 & Monday & $\begin{array}{l}\text { Evaluation of effects (possible remaining effects from last Saturday), } \\
\text { no test product application }\end{array}$ \\
\hline \multicolumn{2}{|c|}{ Rest of week 4, week 5} & Rest phase \\
\hline \multirow[t]{6}{*}{6} & Monday & $\begin{array}{l}\text { Evaluation of effects (control reading before 1st application on naïve skin), } \\
1 \text { st application on naïve skin }\end{array}$ \\
\hline & Tuesday & Evaluation of effects, 2nd application, same site as Monday week 5 \\
\hline & Wednesday & Evaluation of effects, 3rd application, same site as Monday week 5 \\
\hline & Thursday & Evaluation of effects, 4th application, same site as Monday week 5 \\
\hline & Friday & Evaluation of effects, no test product application \\
\hline & Saturday/Sunday & Rest phase \\
\hline 7 & Monday & Evaluation of effects (possible remaining effects from last Friday) \\
\hline
\end{tabular}


The intensified version of the Shelanski and Shelanski HRIPT ${ }^{11}$ was used. This method has shown its utility in differentiating between the skin compatibilities of dermatological products. ${ }^{12}$ The schedule of procedures is given in Table II. During a three-week induction phase, each product was applied four times per week at 24hour intervals, e.g., on Monday, Tuesday, Wednesday and Thursday of Weeks 1 and 2 and, Monday of Week 3 being a holiday, on Tuesday, Wednesday, Thursday, and Friday of that week. Each study article was applied on the same site assigned exclusively to it on the back of each participant throughout the induction phase. A two-week rest period without product application followed. During Week 6, challenge applications, sited on an area of naïve skin, were conducted on Monday, Tuesday, Wednesday, and Thursday.

For each application, $150 \mu \mathrm{l}$ of a study article was delivered via micropipette to the absorbent pad of an occlusive patching device (Covidien4022). This device consists of a non-woven carded cotton pad (a 3/4" $\times$ $3 / 4^{\prime \prime}$ Webril coupon) and a cover (a 1.5" $\times 1.5^{\prime \prime}$ water impermeable, adhesive-coated plastic film). The pad was kept uncovered at ambient conditions for $30-60$ seconds, a processing that allowed a portion (4-8mg) of the contents to evaporate. A device prepared in this manner was applied on the left side of the back of each participant on each scheduled application day and left in place 24 hours. The devices applied on Friday of Week 3 were removed on Saturday by the participant, presumably with some help. The skin of the application sites was not examined by a technician until the following Monday. The devices applied on all other days were removed in the clinic by a technician who followed the clinic's standard practice for grading effects. The technician waited $5-10$ minutes to allow the skin to adjust to the uncovered condition and display a stable status before she assigned grades to the effects, or lack thereof. A second technician charged with the duty of applying the devices assessed the effects, as well. The two had to be at one with their assessments. The study supervisor was always at hand to resolve any disagreement and confirm critical assessment values. The supervisor was required to ascertain the validity of an assigned grade whenever, during the induction phase, an effect was assigned a grade of $\geq 2$ or was two or more points less than the grade assigned to that elicited by the preceding application. The supervisor

Table III: Criteria for grading visible changes of skin

\section{Grade Visible changes}

$0 \quad$ None

1

Redness, faint to moderate, entire contact area not involved

2 Redness, moderate, entire contact area involved

3

4

Redness, intense, entire contact area involved

Redness plus oedema and/or papules

\section{Clinical significance}

The product is not an irritant

The product is a weak irritant

The product is a moderately strong irritant

The product is a strong irritant

The product may be a very strong irritant, but sensitization must be ruled out before a definitive attribution can be made

The product is a sensitizer

The product is definitely a sensitizer

6

Redness, etc., plus extension

of effect beyond area of contact 
also checked the validity of assigned grades $>0$ during the challenge phase. Criteria for assigning grades are given in Table III. Follow-up examinations were available should any participant manifest an adverse effect at the end of the study.

\section{Statistical Analysis}

Comparisons between product reaction count data were made using a log-linear analysis. The null hypothesis for these tests was that there were no differences in the reaction counts for the three products tested.

\section{Results}

One-hundred-and-four participants were available for assessment throughout the induction phase, with a maximum of two being absent on any study day. Two subjects dropped out, one after four applications and one after six, for reasons unrelated to the study. Onehundred-and-four completed the challenge phase and provided complete sets of data. Over the four weeks, Product A elicited five responses; Product B, seventythree; and $\mathrm{EtOH}$, two. An overview of the number of reactions and number of subjects showing a reaction is given in Table IV.

All the responses elicited by Product $\mathrm{A}$ and by $\mathrm{EtOH}$ were assigned Grade 1 values. In addition to seventy- one Grade 1 responses, Product B elicited two Grade 2 responses, one during each of Weeks 1 and 6 . Detailed results are given in table 5 .

Statistically significant differences were found between products $A$ and $B(p<0.001)$, all four weeks taken as a whole. Contrast tests for product pairs showed that Product $B$ elicited a significantly higher number of responses than either Product $A(p<0.001)$ or $\mathrm{EtOH}$ $(p<0.001)$. The number of responses elicited by Product A was not significantly different from that elicited by $\mathrm{EtOH}(\mathrm{p}<0.256)$.

Analysis of data for individual weeks: The data for each of Weeks 1, 2, and 6 showed significant differences between pairs similar to those shown for the four weeks as a whole. During Week 3, grading of effect within moments after patch removal was conducted on three days only (Wednesday, Thursday and Friday). Therefore an analysis had to be based on data acquired on three instead of four days. That analysis showed the number of responses elicited by Product B not to be significantly different from the number elicited by Product A $(\mathrm{p}<0.156)$. Despite the shortened period, however, the difference between Product $\mathrm{B}$ and $\mathrm{EtOH}$ was still significant $(p<0.014)$.

Table IV: Number of subjects showing a visible reaction in the different study phases and sum of all effects in all subjects in both phases

Number of subjects responding to the applications

Induction phase

Challenge phase

\begin{tabular}{lcc}
\hline Ethanol $90 \%$ & 1 & 1 \\
\hline Product A & 1 & 3 \\
\hline Product B & 26 & 23 \\
\hline
\end{tabular}

Number of elicited effects

Induction phase

\begin{tabular}{lcc}
\hline Ethanol $90 \%$ & 1 & 1 \\
\hline Product A & 2 & 3 \\
\hline Product B & 42 & 31 \\
\hline
\end{tabular}


Product B displayed a "cog tooth" response curve, i.e., the number of responses increasing with the progression of applications each week and then dropping off over the weekend. The highest number of responses elicited by Product $B$ during the induction phase occurred on Friday of Week 1; somewhat less than one third of those responses persisted over the weekend. The numbers of responses elicited on Friday of Week 2 and Friday of Week 3 were substantially less, and no responses persisted over the weekends. The incremental increases in the numbers of responses elicited by Product $B$ after each of the four challenge applications $(\mathrm{n}=0,2,12,17)$ differed appreciably only once from the numbers the product elicited after each of the first four applications during Week $1(n=$ $0,2,8,17)$.

The examiners conducting the exit examinations did not detect any adverse effects. Accordingly, they discharged the subjects, albeit with a caveat that delayed reactions were still a matter of concern and, should one occur, the investigator was to be notified. Two weeks were allowed to elapse and, since no notification was received, the investigator closed the study.

\section{Discussion}

A consideration of the effects of the products under the test conditions justifies findings that Product $\mathrm{A}$ and $\mathrm{EtOH}$ are not clinically significant skin irritants; that Product B is a weak cumulative irritant; and that no sensitizing propensities from any of the three test agents could be detected.

The HRIPT method used in this study differs from that used in a study of an ethanol-based hand gel. ${ }^{13}$ The intensified method was chosen because it was judged to be more pertinent to the hospital situation or anywhere where daily repetitive use is the norm. Despite the smaller numbers $(n=106)$ than in the hand gel study $(n=224)$, our study made greater demands on a product to provide evidence of skin compatibility. These included a more exacting application schedule (16 vs. 10); longer periods of contact continuity $(96$ hours $\times 4$ vs. 24 hours $\times 10$ ); a volatilization procedure resulting in a negligible evaporation of product from patch $(\leq 5.3 \%$ vs. $100 \%$ loss of volatile components); patch removal by staff members in the clinic, [providing a degree of certainty unattainable in the other method that induction applications lasted for the required time (at 11/12 vs. 0/9 applications)[; and the assessment of effects shortly after removal of patches ( $\leq 10$ minutes vs. 24 hours). Implicit in the use of a 24-h delay in grading of effect is that only effects persisting $>24 \mathrm{~h}$ are worthy of consideration. This disregard of shorter-lived responses eliminates much of the sensitivity required of a method regarded as capable of ascertaining whether or not a product is an irritant, let alone, of distinguishing between the skin's tolerance for different products, especially those with weak irritating propensities. In revealing the manner in which the interaction between product and skin changed with time as described below, the method demonstrated the importance of taking shorter-lived responses into account.

The weekly cog tooth incidence curve as exhibited by Product B is typical of the manner in which weak cumulative irritants behave in the intensified method. The gradual weekly decline in the height of the curve, often seen in these studies, is a sign of the skin's ability to accommodate to the irritant. The accommodation apparently develops gradually over the course of weeks.

Despite the presence of fragrance in one (Product A) neither product showed signs of skin sensitization. What the study did show was the differences in the irritating potentials of the three study articles. Insofar as freedom from experiencing hand dermatitis is a goal, the level of confidence of enjoying such freedom is higher with Product A than Product B. Whether this difference has other, more definitive clinically relevant implications was beyond the scope of the study. Of major interest is that the study failed to show that ethanol is so deleterious to skin as to preclude its use in hand disinfectants. That gives cause to wonder why ethanol is believed to be harmful to the skin. Two of its attributes may give cause for this belief.

1: ethanol exerts a desiccant effect on the skin. A group of hand disinfectants showed varying degrees of this effect in a clinical trial. ${ }^{14}$ There is no doubt that, if left unchecked, the desiccant action of ethanol can have a deleterious effect on the skin. The very early changes seen under magnification ${ }^{15}$ 
can so easily be attenuated before the drying and scaling attain a status of clinical concern, ${ }^{16}$ that ethanol's desiccant activity should not present a hazard serious enough to prevent using it in hand disinfectants.

2: ethanol has an unpleasant effect on an open wound. The concept that something that gives pain is harmful is understandable.
There are, in all likelihood, other reasons that healthcare workers would cite to rationalize their belief that alcohol is too harmful for use in hand rubs. This study provides a sound basis for rejecting whatever rationale one may use to disparage the skin compatibility of ethanol.

Table V: Detailed overview over all skin reactions observed during the study period

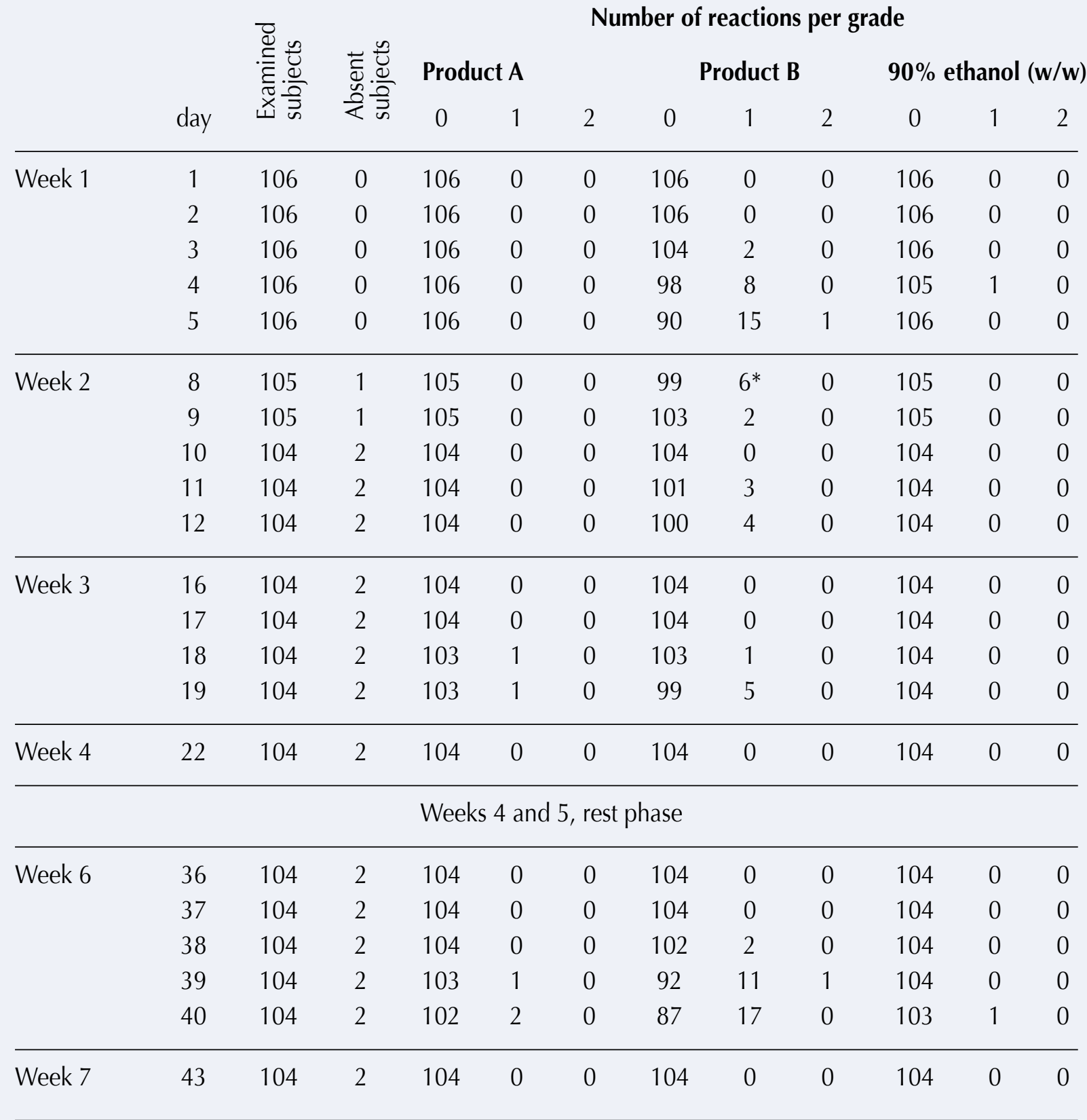

* Five of these effects were found in subjects who showed similar responses on Friday of Week 1. One was found in a subject who had shown no response on Friday. 
An irritant contact dermatitis (ICD) incidence rate of 4.0 per 10000 healthcare workers per year has been reported. ${ }^{17}$ This was slightly below the average ( 4.5 per 10000 workers per year) of twenty-four occupational groups and was based on workers' compensation claims to a local authority. A higher rate of skin irritation was found in healthcare workers compared to the general population $^{18}$ and the incidence of occupational dermatitis in healthcare workers has been reported to be as high as $30 \% .{ }^{19}$ Occupational dermatitis from the use of hand disinfectants undoubtedly contributes to poor compliance in hand hygiene. To assure the highest degree of compliance, the choice of product should be tempered with just as much concern for compatibility as for efficacy.

In conclusion, we showed that high concentrations of ethanol do not render either Product A or Product B too irritating for use in the practice of hand hygiene. There are demonstrable differences in skin compatibility even among qualified products. In essence, this study's findings teach us that there is no justification for forgoing the use of ethanol in hand disinfectants. To do so would deprive the health care worker of the considerable benefits to be gained from an outstanding hand disinfecting agent.

\section{Acknowledgements}

The authors would like to thank Victor Morin, Ecolab Inc., St. Paul, MN, USA for statistical analysis of the data and Ecolab GmbH\&Co OHG, Düsseldorf, Germany for funding the study.

\section{References}

1. Anonymous. $\mathrm{WHO}$ guidelines on hand hygiene in health care (advanced draft), Geneva 2005, http://www.who.int/ patientsafety/events/05/HH_en.pdf

2. Laustsen S, Lund E, Bibby BM, Kristensen B, Thulstrup AM, Kjolsth Moller J. Cohort study of adherence to correct hand antisepsis before and after performance of clinical procedures. Infection Control and Hospital Epidemiology 2009; 30: 172178.

3. Pittet D. Improving adherence to hand hygiene practice: A multidisciplinary approach. Emerging Infectious Diseases 2001; 7: 234-240.
4. Chittaro M, Calligaris L, Farneti F, Faruzzo A, Panaritri M, Brusaferro S. Healthcare workers' compliance with hand hygiene after the introduction of an alcohol-based handrub. International Journal of Infection Control 2009; v5:i1, http:// www.ijic.info/article/view/2490/2799

5. Pedersen LK, Held E, Johansen JD, Agner T. Less skin irritation from alcohol-based disinfectant than from detergent used for hand disinfection. British Journal of Dermatology 2005; 153: 1142-1146.

6. Slotosch CM, Kampf G, Löffler H. Effect of disinfectants and detergents on skin irritation. Contact Dermatitis 2007; 57: 235-241.

7. Löffler H, Kampf G, Schmermund D, Maibach H. How irritant is alcohol? British Journal of Dermatology 2007; 157: 74-81.

8. Stutz N, Becker D, Jappe U, et al. Nurses' perception of the benefits and adverse effects of hand disinfection: a multicenter questionnaire study with additional patch testing by the German Contact Dermatitis Research Group. British Journal of Dermatology 2009; 160: 565-572.

9. Kac G, Podglajen I, Gueneret M, Vaupré S, Bissery A, Meyer G. Microbiological evaluation of two hand hygiene procedures achieved by healthcare workers during routine patient care: a randomized study. Journal of Hospital Infection 2005; 60: 3239.

10. Girou E, Loyeau S, Legrand P, Oppein F, Brun-Buisson C. Efficacy of handrubbing with alcohol based solution versus standard handwashing with antiseptic soap: randomised clinical trial. British Medical Journal 2002; 325: 362-365.

11. Shelanski HA, Shelanski MV. A New Technique of Human Patch Tests. Toilet Goods Association Proceedings for the Scientific Section, No.19, May 1953, 46-49.

12. Shelanski MV, Philips SB, Potts CE. Evaluation of Cutaneous Reactivity of Recently Marketed Dermatological Products. International Journal of Dermatology 1996; 35: 137-140.

13. Kampf G, Muscatiello M, Segger D. Dermal tolerance and effect on skin hydration of an improved ethanol-based hand gel. International Journal of Infection Control 2009, v5:i1; http://www.ijic.info/article/view/2922/2800

14. Kramer A, Bernig T, Kampf G. Clinical double-blind trial on the dermal tolerance and user acceptability of six alcohol-based hand disinfectants for hygienic hand disinfection. Journal of Hospital Infection 2002; 51: 114-120.

15. Shelanski MV, Sadiq I, Nicholson JE. Skin compatibility of pure alcohols versus formulated products. $9^{\text {th }}$ International Congress of the German Society of Hospital Hygiene, 2008.

16. Sadiq I, Crosby M, Nicholson JE, Shelanski MV. Method of assessing the pre-clinical drying/scaling effects of alcoholbased hand disinfectants. The Journal of Investigative Dermatology, 129: Supplement, 1 April 2009, p. 57, poster No. 338.

17. Dickel H, Kuss O, Schmidt A, Kretz J, Diepgen TL. Importance of irritant contact dermatitis in occupational skin disease. American Journal of Clinical Dermatology 2002; 3: 283-289.

18. Larson E, Girard R, Pessoa-Silva CL, Boyce J, Donaldson L, Pittet $\mathrm{D}$. Skin reactions related to hand hygiene and selection of hand hygiene products. American Journal of Infection Control 2006; 34: 627-635.

19. Kampf G, Löffler H. Dermatological aspects of a successful introduction and continuation of alcohol-based hand rubs for hygienic hand disinfection. Journal of Hospital Infection 2003; 55: 1-7. 